\title{
Dead or alive: The elusive quest for long-term follow-up
}

\author{
Carlos M. Mery, MD, MPH
}

\author{
From the Division of Congenital Heart Surgery, Department of Surgery, Texas Children's Hospital, Baylor Col- \\ lege of Medicine, Houston, Tex. \\ Disclosures: Author has nothing to disclose with regard to commercial support. \\ Received for publication April 19, 2017; accepted for publication April 21, 2017; available ahead of print May 24, \\ 2017. \\ Address for reprints: Carlos M. Mery, MD, MPH, Division of Congenital Heart Surgery, Texas Children's Hos- \\ pital, 6621 Fannin St, MC19345H, Houston, TX 77030 (E-mail: cmmery@texaschildrens.org). \\ J Thorac Cardiovasc Surg 2017;154:647-8 \\ $0022-5223 / \$ 36.00$ \\ Copyright (C) 2017 by The American Association for Thoracic Surgery \\ http://dx.doi.org/10.1016/j.jtcvs.2017.04.054
}

Accurate ascertainment of vital status is a critical component of medical research and quality improvement programs, and one of the most difficult to achieve. Researchers in the United States have relied on a combination of tools in addition to the traditional local techniques of searching the medical record, calling patients, and screening obituaries. The 2 most important tools used in the past were the Social Security Death Master File (SSDMF), ${ }^{1}$ also known as Social Security Death Index, and the National Death Index (NDI) from the Centers for Disease Control and Prevention. ${ }^{2}$

The SSDMF is a database collected from death reports received by the Social Security Administration (SSA) from many sources to administer its programs. In 1980, after a legal ruling, the SSA started providing public access to the entire master file. ${ }^{3}$ In November 2011, however, after concerns arose about identity theft of recently deceased individuals and the argument was made that the SSA is not justified to disclose information provided by individual states, all death records received from states were removed. This amounted to removing 4.2 of the 89 million records that the file contained in 2011 and translated into adding 1 million fewer records annually. ${ }^{4}$ The SSA now keeps 2 separate files: the "full file," which is shared only with federal and state agencies, and the "public file," which excludes death data received from states. As such, the SSDMF is no longer a reliable source of follow-up information. 5,6 $^{5}$

The NDI is a resource that collects data directly from the states and provides information to clinical investigators. ${ }^{2}$ Even though the NDI has always been a more reliable source of data than the SSDMF (sensitivity $87 \%-98 \%$ for NDI vs $83 \%-84 \%$ for SSDMF $)^{7-9}$ and contains information on cause of death, it requires an application that takes 2 to 3 months to be approved, is available 15 to 16 months after the end of the respective calendar year, and is relatively expensive, especially for large data sets (eg, 1000 records searched against 10 years would cost $\$ 1850)$. $^{2}$

The advantages of being able to link large data sets such as the Society of Thoracic Surgeons (STS) Database to vital status registries for quality assurance purposes would be

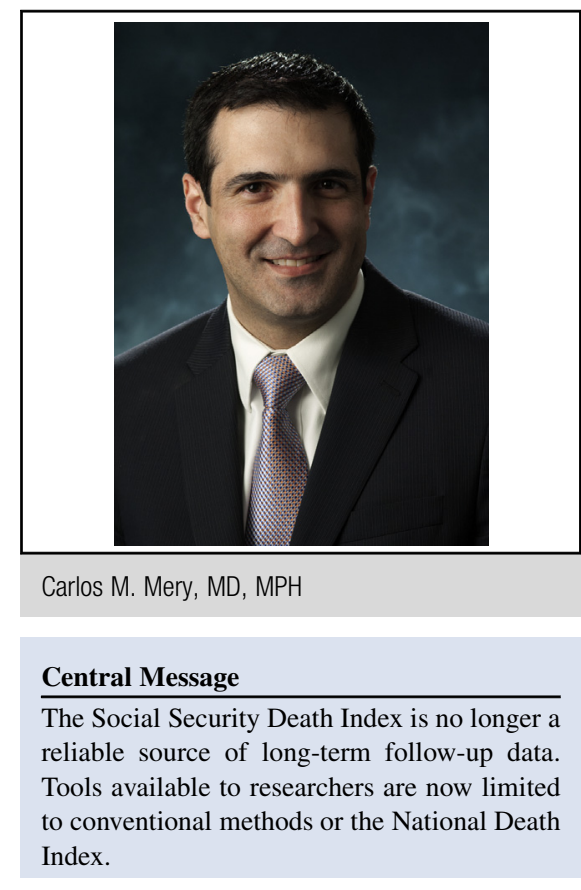

See Article page 644.

tremendous. In 2011, Jacobs and associates ${ }^{10}$ proved that linking the STS Database to the SSDMF was feasible, opening the door to the possibility of providing each participating program with long-term survival data as part of their regular report. The STS is to be commended for their continuous efforts in exploring different options, as explained by Jacobs and colleagues ${ }^{6}$ in this issue of the Journal.

So, what options do medical researchers currently have to obtain follow-up data? Unless they are able and willing to invest the time and resources needed to obtain data from the NDI, local traditional methods may be the only way. It is ironic that in 2017, in the middle of the digital and social media age, we remain stuck hoping that, one by one, each of a study's subjects will pick up the phone when we call them, and let us know whether they are dead or alive.

\section{References}

1. Social Security Administration. Requesting the full Death Master File (DMF). Available at: https://www.ssa.gov/dataexchange/request_dmf.html. Accessed April 18, 2017.

2. Centers for Disease Control and Prevention. National Death Index. Available at: https://www.cdc.gov/nchs/ndi/. Accessed April 18, 2017.

3. Mathews BJ. Massachusetts Genealogy Council Civil Records Committee: identity theft, tax fraud, and the Death Master File Timeline, January 19, 2015. Available at: http://www.fgs.org/rpac/wp-content/uploads/2010/02/SSDI-timeline19-Jan-2015.pdf. Accessed April 18, 2017. 
4. US Department of Commerce, National Technical Information Service. Important notice: change in Public Death Master File records. Available at: https://classic.ntis.gov/assets/pdf/import-change-dmf.pdf. Accessed April 18, 2017.

5. Peterss S, Charilaou P, Ziganshin BA, Elefteriades JA. Assessment of survival in retrospective studies: the Social Security Death Index is not adequate for estimation. J Thorac Cardiovasc Surg. 2017;153:899-901.

6. Jacobs JP, Yohe C, Krantz J, Blackstone EH. Documentation of vital status in the United States of America. J Thorac Cardiovasc Surg. 2017;154:644-6.

7. Cowper DC, Kubal JD, Maynard C, Hynes DM. A primer and comparative review of major US mortality databases. Am Epidemiol. 2002;12:462-8.
8. Curb JD, Ford CE, Pressel S, Palmer M, Babcock C, Hawkins CM. Ascertainment of vital status through the National Death Index and the Social Security Administration. Am J Epidemiol. 1985;121:754-66.

9. Binswanger IA, Morenoff JD, Chilcote CA, Harding DJ. Ascertainment of vital status among people with criminal justice involvement using Department of Corrections records, the US National Death Index, and Social Security Master Death Files. Am J Epidemiol. April 6, 2017 [Epub ahead of print].

10. Jacobs JP, Edwards FH, Shahian DM, Prager RL, Wright CD, Puskas JD, et al Successful linking of the Society of Thoracic Surgeons Database to Social Security data to examine survival after cardiac operations. Ann Thorac Surg. 2011;92 32-7; discussion 38-9. 